"Interior view of a hut ...": Stereography and the depiction of an Interior Architecture in 1930

Peter Wood \& Michael Dudding, School of Architecture, Te Herenga Waka Victoria University

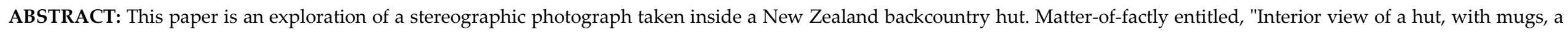

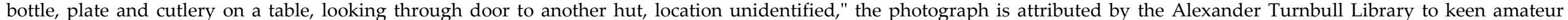

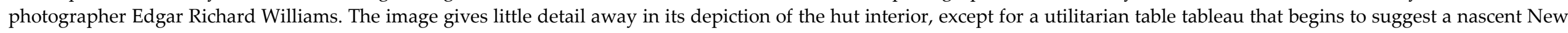

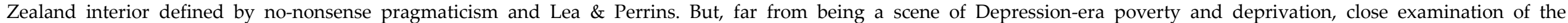

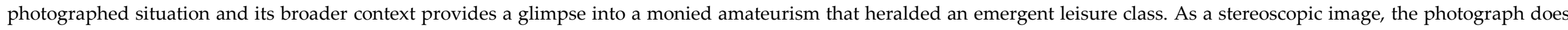

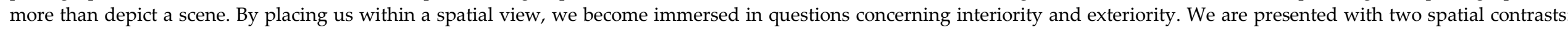

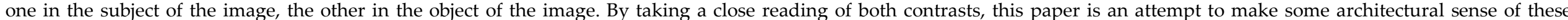
dualities.

A stereoscope is an instrument which makes surfaces look solid. All pictures in which perspective and light and shade are properly managed, have more or less of the effect of solidity; but by this instrument that effect if so heightened as to produce an appearance of reality which cheats the senses with its seeming truth. ${ }^{1}$

This paper is an exploration of a photograph taken inside a New Zealand backcountry hut. This is an image that emphasises the interior of the hut, but within the open door is framed a view of another hut in a rural setting. Stark juxtaposition of interior and exterior scenes offers a compelling theatricality to such a modest setting. However, the obvious curiosity to this image is that it is composed of a pair of near-identical photographs which, when viewed through a device known as a stereoscope, would present a three-

${ }^{1}$ Holmes "The stereoscope and the Stereograph" p 742.

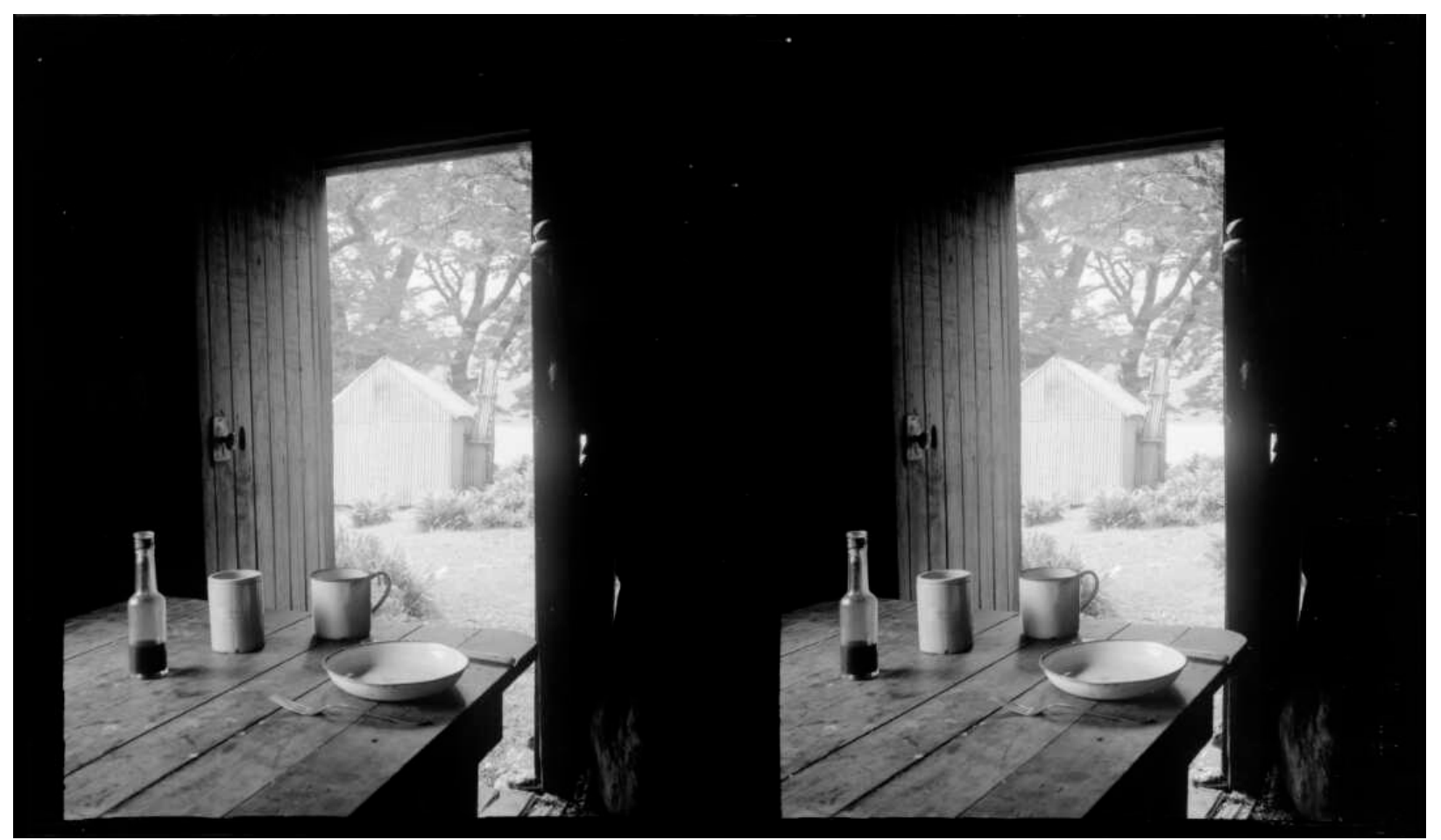

Figure 1: "Interior view of a hut, with mugs, a bottle, plate and cutlery on a table, looking through door to another hut, location unidentified" (c1910-39) Williams, Edgar Richard 1891-1983: Negatives, lantern slides, stereographs, colour transparencies, monochrome prints, photographic ephemera. Ref: 1/2-187782-F. Alexander Turnbull Library. 
dimensional effect to a viewer. The significance of this is that stereoscopic photography, by placing us within a spatial view, is also immersed in questions concerning interiority and exteriority. So, we have two spatial contrasts: one in the subject of the image, the other in the object of the image. What follows is an attempt to make some architectural sense of these dualities.

The image under analysis is one of a significant number of stereoscopic photographs (stereograms) held by the Alexander Turnbull Library (ATL) as the work of Edgar Richard Williams. Little is known about Williams, an uncertainty also found in the wide period of production attributed to many of his photographs, including this one which is dated to c1910-30 (narrowing this timeframe will be a necessary step in order to work with this image). Making attribution more difficult is the presence of stereoscopic images in the ATL made by Williams' father, William Williams (1859-1948). Indeed, in one dated to 1903, we find the entire Williams family on a horsedrawn carriage with Edgar, born in 1891, sitting on the back as an adolescent. This, however, does set some useful parameters on the period in which "Interior of a hut ..." was recorded. It also introduces the distinct possibility that Edgar inherited both his photographic interest and his stereoscopic equipment from his father. ${ }^{2}$

Whatever the specifics might be, we can say with assurance that Edgar Richard Williams was a keen amateur photographer and that a great many of his stereographic images record the other great interest in his life: mountaineering. It is in this crossover that the image under examination here was produced.

\section{Tramping in New Zealand}

We won't dwell on the development of tramping in New Zealand beyond a basic precis. Johnston and Pawson have noted that ideas forming mountain recreation start near the end of the nineteenth century. In European climbing, the mountain landscape

\footnotetext{
${ }^{2}$ Mention can be found of William Williams' activity as an amateur stereoscopic photographer in newspapers of the time. In November, 1898, he was awarded first prize in stereoscopic photography by the Queensland

Photographic Society ("Dunedin Photographic Society" p 2). The following year Williams delivered a paper on stereoscopic photography to the Dunedin Photographic Society ("Friday, June 23, 1899" p 4). Later that same year he also received second place in stereoscopic photography in the Sydney Photographic Exhibition ("Sydney Photographic Exhibition" p 3).
}

was seen as uniting themes of scientific discovery and mysticism. Following colonial routes to the southern hemisphere, these notions evolved to include a distinctly antipodean interest in sporting activities forged in themes of nationalism and military purpose. $^{3}$ However, embrace of mountainbased activities was slow beyond a small core until after 1920. ${ }^{4}$ Numbers increased through the 1930s so that, by 1937, the newly created Physical Welfare and Recreation Act included provision for recreation facilities in national parks and state forests. ${ }^{5}$

What is often forgotten in the New Zealander's passionate appeal to the beauty of the countryside and its democratic availability, is that these first social explorations were the prerogative of an emerging leisure class who had both sufficient time and sufficient money to spend extended

\footnotetext{
${ }^{3}$ Johnston and Pawson "Challenge and danger" p 175.

${ }^{4}$ The first "official" tramping organisation was the Tararua Tramping Club, formed in 1919. This was established shortly after the New Zealand Alpine Club, New Zealand's first outdoor recreation club, was established. (Kearns and Fagan "Sleeping with the past?" p 118).

${ }^{5}$ Johnston and Pawson " Challenge and Danger in the Development of Mountain Recreation in New Zealand" p 175.
} 
periods in the mountains.

Roland Barthes was to advance mountaineering as a bourgeois invention, and it is the case that mountaineering activity and the bourgeoisie grew in parallel in the first half of the nineteenth century throughout Europe. ${ }^{6}$ Speaking of Europe, but by no means excluding the pattern of mountaineering popularity in New Zealand:

The founders of climbing as a recreation, and eventually as a sport, were primarily from the new industrial and intellectual upper middle classes of the mid-nineteenth century. ${ }^{7}$

Similarly, Peter Hansen has written of how "mountaineering was invented at the intersection of contemporary definitions of middle-class gentility and status, gender, and national identity."8 We need to be attentive to these conclusions, as they offer important social and cultural transparency for any visual critique of the area, and here this is not limited to mountaineering.

\footnotetext{
${ }^{6}$ Donnelly "Social Climbing" p 16.

${ }^{7}$ Donnelly "Social Climbing" p 16.

${ }^{8}$ Hansen "Albert Smith, the Alpine Club, and the

Invention of Mountaineering in Mid-Victorian Britain" $\mathrm{p}$ 301.
}

It should be noted that photography was attached to the rise of a monied middle-class and the rise of consumerism. Its beginning lay in scientific discovery; the early commercial realisations required early photographers to be chemists, engineers, artists, and impresario. But the introduction of the Brownie camera by Eastman Kodak in 1900 democratised photography, making it available to the middle-classes in an unprecedented way. Or, as Walter Benjamin would see as closely as 1934, the photographer "came to every customer as a member of a rising class and enclosed him in an aura which extended even to the folds of his coat or the turn of his bow tie." 9

What we have in this modest image, we suspect, is a fascinating moment in the formation New Zealand's social structure, and we need to be mindful when moving forward that this is now a story of exclusion.

\section{Table Tableau}

The central focus of the composition is a table setting featuring a spartan arrangement for one, consisting of a mug, plate, knife and fork, and two probable condiment containers.

${ }^{9}$ Benjamin "A Short History of Photography" p 19.
There is no indication that a meal is either imminent nor accomplished, and it seems more than probable that the assembly serves the interests of stereographic photography by providing a strong foreground focal point. But we should not dismiss the contents of this scene as irrelevant. Just as it seems likely that the arrangement was contrived by the photographer, equally, it seems just as likely that the items for display were drawn from their immediate surroundings. That is, this may be a visually edited preparation, but the elements are indigenous to the hut and so add important contextual information to the photograph. So, it is that we need to turn to these articles with sharp attention.

Behind the plate is an open stoneware container. In detail, it displays the gloss of a glaze and has distinctive vertical relief stripes culminating in an incised lip. There is a label applied to the container, but this, unfortunately, remains illegible. Nonetheless, we can say with some certainty that it is an example of an English stoneware jam pot. We might even go a little further and say that this is specifically an example of Hartley's preserves, dating to the 1920 s.

As a digression to this story, Hartley's was 
one of the largest manufacturers of preserves in the UK. The company's success was sufficient such that, in 1888, it developed a purpose-built village for its key employees. Designed by father and son architects William Sugden and William Larner Sugden, Hartley's Village consisted of 49 houses organised around a green, linked by roads named after jam ingredients (Sugar Street, Red Current Court, Cherry Row, and the like). ${ }^{10}$

The bottle to the left of the jam pot offers fewer distinguishing features for identification. It is, in most ways, a standard condiments bottle. The straight sides and a long neck are typical of a plain 'club style' sauce bottle. This one sports a cork and glass closure but no evident embossing of the glass. In the period that we understand this photograph to be taken, the dominant examples of this bottle shape can be associated with Lea \& Perrins Worcestershire sauce. The dark contents of the depicted bottle lend some credence to this association, despite the lack of a label.

The arrival of Lea \& Perrins sauce to New Zealand can be dated to at least 1886 (through

\footnotetext{
10 "Hartley's" n.p.
}

the discovery of an undamaged bottle during archaeological excavations of the Buried Village of Te Wairoa, destroyed by the eruption of Mt Tarawera in June that year). ${ }^{11}$ It says something that by 1889 , an advertisement in Southland Times promoted a Worcestershire sauce being made in Dunedin as being "as equal in quality to the imported sauce at half the price."12 Added to this, by 1907 the Otago Witness published a DIY recipe for Worcestershire sauce featuring Soy sauce, Madeira wine, brandy and boiled hogs liver water. ${ }^{13}$

To return to the object under review, it seems probable that this is a Lea \& Perrins bottle, but we cannot with certainty conclude that this makes the contents Lea \& Perrins sauce. What we can say is that examples of non-embossed Lea \& Perrins bottles are available by 1930 .

The centrepiece pairing of the table setting is an enamelware mug and a high-sided plate. Enamelware is produced by fusing powdered glass onto a pressed tin form; the result is durable tableware that is lighter, easier to

${ }^{11}$ Shurtleff and Aoyagi History of Worcestershire Sauce p 169.

12 "Gawne's Worcester Sauce [advertisement]" p 3.

13 "Notes and Queries" p 47. clean, and less fragile than traditional chinaware. These qualities set the social status of enamelware as distinctly low, but this pragmatic durability carved out a specialist role for enamelware in the casual domesticity of New Zealand backcountry living.

In a country where national identity, especially that of Pākehā, is tied to constructions of pragmatic, utilitarian nononsense, ${ }^{14}$ enamelware has become emblematic of a "real" New Zealand character. A literal manifestation of this image can be found in an iconic photograph of Edmund Hillary and Tenzing Norgay, immediately upon their return from the peak of Everest. In the glow of their extraordinary triumph, Hillary is shown holding an enamel mug emblazoned with his surname so as to culturally fuse physical fortitude, New Zealand identity and enamelware as synonymous. Indeed, so pervasive is this representation that tourism shops throughout New Zealand stock nationalistically coded enamelware mugs, while active-wear clothing brand Edmund Hillary sell a reproduction version of their namesake's drinking vessel. ${ }^{15}$

\footnotetext{
${ }^{14}$ Belich Paradise Reforged.

${ }^{15}$ For a fascinating critique of the social and cultural norms the framed the asymmetrical celebration of
} 
Unfortunately, this does little to help date the hut interior. Originally marketed as a safe alternative to other toxic materials, mass production of enamelware began in the USA in the 1870 s and continued through to the 1930s. ${ }^{16}$

The final component of the dining tableau is the knife and fork. Historical photographs tend to present the past with a chronological consistency, locking image content to one moment in time. But here, the knife and fork are important anomalies. Whereas the enamelware and the accompanying bottle and jar can be made contemporaneous as domestic objects of practical opportunity, the knife and fork are outsiders.

Let us begin with the fork. Even in a black and white photograph, the slight sheen to the fork surface strongly suggests electroplated nickel silver (EPNS), which had replaced sterling silver as a cheaper substitute through the nineteenth century. The fork is plain in design, with four elongated tines and no apparent decoration. This suggests a pattern

Hillary and Norgay following their successful climb of Everest, see Gilchrist "The politics of totemic sporting heroes and the conquest of Everest."

${ }^{16}$ Wilkniss "Enamelware - a collector's guide" n.p. consistent with an Old English design of the late Edwardian period. Beyond this, there is little that can be ascertained from the fork. However, the knife, despite being largely obscured behind the enamel plate, nonetheless offers a more interesting window.

Read as a companion to the standard English fork pattern, it would be an easy conclusion to make that the dining knife might be an Old English pattern bone handled one. However, close inspection of the handle, while not obviously excluding bone as a possible material, does reveal distinctive fluting and a small shield addition. This displays a striking resemblance to a table knife found in an advertisement for Walker \& Hall Ltd and is an example of their "non-stain" cutlery line. Significantly, this association identifies it as an early example of stainless-steel cutlery.

The composition of modern stainless steel was perfected in 1913, and a formal public announcement followed in The New York Times in 1915. Yet, even by 1920, the Tuapeka Times in New Zealand carried advertisements selling the advantages of "finest Sheffield" stainless steel cutlery. ${ }^{17}$ We also know that

17 "New Stainless Rustless Cultery [advertisement]" p 4.
Walker \& Hall established two showrooms in New Zealand: the first in Wellington in 1911, and the second in Auckland three years later. ${ }^{18}$ Thus, the availability of this firm's latest product in New Zealand is not in doubt. Added to this, an advertisement for this table knife is branded under Walker \& Hall Ltd., signaling a limited liability legal status for Walker \& Hall that was not enacted until 1920. ${ }^{19}$ So, we can reasonably conclude that the knife could not have been sold in New Zealand prior to 1920 . This is an important fact.

We can extract from these observations that the rudimentary fabric of the hut should not be misunderstood as an indication of impoverishment. Indeed, it is quite the opposite. As we have seen, the artefacts set upon the table collect together items of convivence (the jar) but also objects that are probably borrowed from a far more stable and affluent architecture (the knife and fork). We can add that the presence of a camera and a photographer indicate an amateur activity that requires some wealth and education. And finally, we need to see the entire scene within

${ }^{18}$ Giorgio B "Walker and Hall" n.p. 
the socio-economic setting of an emergent leisure class.

Perhaps the most surprising finding to take away from this table setting is that it existed at all in this location. In a hut that seems short on other formalities, a set dining experience is an extravagance. But, we need a table setting to have table manners. As Fred Schrader has pointed out, table manners are another bourgeois invention: membership in a cultural elite demonstrated by "taste."20

\section{A Brief History of Stereographs}

So far, this paper has been concerned with describing and dating the selected photograph. This serves to confirm it as a suitable subject for this forum and to demonstrate the value in detailed visual analysis as a valid historiographical methodology. As an extension to this second line of argument, it was suggested that the photograph "Interior view of a hut ..." contained coded messages concerning tramping and an emergent leisure class in New Zealand.

\footnotetext{
${ }^{20}$ Fred Schrader, quoted in Wendling "Sovereign Consumption as a Species of Communist Theory" p 44.
}

However, what will be painfully obvious in its absence, is any mention that this is far from a conventional photograph. In taking only the subject of the image, we have been able to discuss the compositional contents as uncomplicated unified topics, but the striking immediacy of this image as an object is that it composed a seemingly identical pair.

We say seemingly, but there is, in fact, a minor variation in optical geometry between the two images that correspond to the physiology of binocular vision and which quickly identifies this as a stereograph. Unfortunately, the profundity of stereographic photography is lost when viewed remotely, either through the internet or via a PowerPoint presentation. But were we able to view this pairing through a stereoscope, the optical effect would be to produce from these flat photographs a threedimensional effect. This might sound like a device of novelty, especially when its origins are traced to the late nineteenth century, but there is more to the conceptual representation created by a stereograph than its deployment as entertainment might suggest.

The remainder of this paper will be given over to exploring the representational implications of the stereograph as a recorder of architectural space, with special attention being afforded to the specifics of how the stereographic image "Interior of a hut ..." conflates identities of subject and object while simultaneously creating an opposition between interior (interiority) and landscape (exteriority) that all but obliterates a conventional architecture of building. To achieve this, it is necessary to recount the origins of the stereograph and to give this an experiential context.

\section{The Stereoscope}

The terms stereograph, stereograms, stereoview, and stereocards ${ }^{21}$ relate to an optical effect whereby two separate images of a single object, seen from slightly divergent angles consistent with the geometry of binocular vision, can be viewed in such a way that an effect of three dimensionality is made manifest to a viewer.

Stereograms replicate the working of our vision. As our eyes are set apart, the visual information retrieved differs from one side to that of the other so that our left eye sees slightly more of the left side of the world and

\footnotetext{
${ }^{21}$ Spiro History through the Stereoscope $\mathrm{p} 1$.
} 
our right eye sees slightly more of the right side of the world. It is one of the wonders of the human brain that it is able to synthesis these two information sources into a single view. We understand this as the binocular vision that provides us with the ability to perceive depth.

In order to manufacture such a view, a scene is recorded photographically using two lenses offset consistently with the geometric offset of our own eyes. If the resulting images are viewed discreetly - left image to the left eye, right image to the right eye - our brains happily combine these two photographs into a new one with the appearance of spatial depth. When viewed through an appropriate device, a stereoscopic image can seem staggeringly "real."

Charles Wheatstone first described the scientific basis of stereopsis in 1838 in a paper delivered to the Royal Society. ${ }^{22}$ With illustrations of his own making, Wheatstone gave simple examples of how the difference between left and right eye perception might be drawn. He also provided a design for a

${ }^{22}$ Wheatstone "Contributions to the Physiology of Vision" pp 371-394. viewing apparatus that used mirrors to direct the eye to a resolved image. Yet, while being extensive in length, Wheatstone's essay is short on argument regarding the actual physiological mechanism for the phenomenon. His findings were, he stated, merely a product of descriptive geometry as defined by Monge, ${ }^{23}$ but after these conflicting images entered the eye, he had nothing to add to any scientific explanation.

Wheatstone's device would seem an obvious servant to the advances of photography, but we need to remember that this prescient essay was delivered in the year preceding Louis Daguerre's announcement of the daguerreotype and the presentation to the Royal Institution by Wheatstone's friend William Henry Fox Talbot on his advances in the area of calotype photography.

Wheatstone's stereoscope was a cumbersome arrangement that required manipulating mirrors on a large stand to separate the binocular vision of the observer. The breakthrough that popularised stereography was the lenticular lens, invented by Sir David

${ }^{23}$ Wheatstone "Contributions to the Physiology of Vision" p 377.
Brewster in 1849. By manipulating the eye directly through a glass lens, Brewster was able to eliminate Wheatstone's mirrors to produce a viewing instrument that was convenient and inexpensive. Brewster's stereoscope went on to make a significant impression to all those who first encountered it at the Great Exhibition of 1851, including Queen Victoria herself, who endorsed it loudly. ${ }^{24}$ However, it needed the additional development of American Olivier Wendell Holmes in 1861 to make it a truly portable device and so ensure its availability to even modest households. The stereoscope would become so successful that it could, in the words of Robert Silverman, be considered the "consummate Victorian amusement."25

The rise in popularity of the stereoscope coincided with the emergence of experimental psychology and found a place in university laboratories. However, for the greater part, the stereoscope belonged to a class of "philosophical toy," which, along with the kaleidoscope and the zoetrope, provided entertainment while demonstrating scientific

${ }^{24}$ Silverman "The Stereoscope and Photographic Depiction in the late 19th Century" p 735.

${ }^{25}$ Silverman "The Stereoscope and Photographic Depiction in the late 19th Century" p 730. 
principles. ${ }^{26}$ Indeed, by 1856, Robert Hunt, an English photographic chemist, was able to describe the stereoscope as having a place in drawing room, in philosophers talks, and in children's play. ${ }^{27}$

New Zealand newspapers first mention the stereoscope in 1852 as a scientific aside. ${ }^{28}$ But its role as a popular and entertaining curio was established here as quickly as in 1857, with advertisements for "a fresh assortment of Stereoscopes and Stereoscopic Views," including some "very pleasing domestic groups," available directly from "wharf stores" (that is, straight off the ship). ${ }^{29}$ By 1860, JS Norrie, a photographic chemist of Sydney, was advertising "folding stereoscopic cameras" to the New Zealand market. ${ }^{30}$ This was followed later that same year by a classified advertisement in the Lyttelton Times by one HE Alport for his second-hand equipment and its associated paraphernalia. ${ }^{31}$

While not advertised in New Zealand

\footnotetext{
${ }^{26}$ Silverman "The Stereoscope and Photographic Depiction in the late 19th Century" p 730.

${ }^{27}$ Hunt "The Stereoscope" p 118.

28 "English Extracts" p 3.

29 "Wharf Stores, Shortland Street [advertisement]" p 1.

${ }^{30}$ Norrie "Photography [advertisement]" p 2.

31 "Valuable Photographic Camera for Sale" p 5.
}

newspapers, mention should nonetheless be made of the role of the stereoscope as an instrument for the dissemination of pornographic images. ${ }^{32}$ And it may be a fact that remains true today, that the pornographic industry has always been an uncomfortable trailblazer in the adoption of emergent technologies. ${ }^{33}$

Colligan has argued that the stereoscope coincided with a wider Victorian fascination with capturing realism. In the case of the stereograph, the Victorians found a different form of realism that constructed threedimensional space rather than a clutter of details, with the effect of absorbing the viewer "into the image." ${ }^{34}$ The visual impact of this absorption exceeds usual expectations of conventional photographic imagery, in which the subject might seduce, amaze, or shock, but which nevertheless remains looked at rather than into:

\footnotetext{
${ }^{32}$ The Lyttleton Times reported in November, 1906, that Auckland police had raided the shop of bookseller, Josiah Conolly, and seized sixty immoral publications and nineteen indecent stereoscopic pictures. "Town and Country" p 6.

${ }^{33}$ O'Toole Pornocopia p 274.

${ }^{34}$ Colligan "Stereograph" p 76.
}

The reality effect produced by the stereoscope is variable: objects in the middle or far distance appear to be arranged along planes separated from each other by a void; while objects in the foreground, solid enough to touch, assume astonishing palpability. ${ }^{35}$

By appealing directly to the physiological operations of the eye and removing all peripheral influence, the stereograph places us into the image. The optical impression of this is not perfect, but it is sufficiently involving to remove observational distance found not only in photography but also in all forms of pictorial representation.

The profundity of the stereograph lies not just in the creation of a three-dimensional visual experience, but rather the consequence of that experience shifting the viewer's experience from outside the image to inside it. Jonathan Crary, in one of the few recent examinations of stereographic photography, emphasises that the desired effect of the stereoscope was not likeness but immediate apparent tangibility. ${ }^{36}$ Even that great nineteenthcentury physicist, Hermann von Helmholtz, found himself seduced by the visual immersion of the stereoscope:

\footnotetext{
35 Trotter "Stereoscopy" p 41.

${ }^{36}$ Crary Techniques of the Observer $\mathrm{p} 124$
} 
These stereoscopic photographs are so true to nature and so lifelike in their portrayal of material things, that after viewing such a picture and recognizing in it some object like a house, for instance, we get the impression, when we actually see the object, that we have already seen it before and are more or less familiar with it. ${ }^{37}$

In Crary's opinion, no other representation of the nineteenth century so conflated the real with the optical. This effect was particularly magnified when applied to the Victorian interior, as the most intense stereoscopic experiences seemed tied to object-filled spaces:

with a material plenitude that bespeaks a nineteenthcentury bourgeois horror of the void; and there are endless quantities of stereo cards showing interiors crammed with bric-a-brac, densely filled museum sculpture galleries and congested city views. ${ }^{38}$

Crary's point is that overcrowded space is particularly suited to stereographic imagery as it facilitates the planar characteristic of the technique. He continues:

We perceive individual elements as flat, cutout forms arrayed either nearer of further from us. But the experience of space between these objects (planes) is not one of gradual and predictable recession; rather, there is a vertiginous uncertainty about the distance separating

\footnotetext{
${ }^{37}$ von Helmholtz Treatise on Physiological Optics p 303.
}

${ }^{38}$ Crary Techniques of the Observer $\mathrm{p} 125$. forms. Compared to the strange insubstantiality of objects and figures located in the middle ground, the absolutely airless space surrounding them has a disturbing palpability. ${ }^{39}$

It is accepted that the earliest photographs frequently took architectural scenes as their focus for the simple fact that the required exposure times demanded a subject that would not move. ${ }^{40}$ Take, for example, the image that is recognised as the world's first photograph: the heliograph, taken in 1828 by French scientist Joseph Nicéphore Niépce, depicting a view of a collection of buildings captured from an upstairs window. Or one of the earliest surviving calotype images, taken by William Henry Fox Talbot of his own house, Lacock Abbey, in 1835. The first photograph of a living person was, in fact, captured within an urban scene; the bootblack and client in the lower right corner of Duguerrre's 1938 photograph of the View of the Boulevard du Temple. In truth, that scene was full of urban life, including horse and cart traffic and pedestrians, but the ten-minute exposure time meant these other moving

${ }^{39}$ Crary Techniques of the Observer $\mathrm{p} 125$.

${ }^{40}$ Zimmerman Photographic Architecture in the Twentieth Century p 2. subjects could not register in the fixed image in the same way as the relatively stationary transaction between the bootblack and his gentleman customer.

However, there is an early observance that stereography was particularly suited to the recording of architecture. Reviewing the rapid development of the stereoscope in 1859, Oliver Wendell Holmes wrote of stereoscopic views of the arches of Constantine that they rendered the grain of the stone itself, and of the Parthenon pediment, that we may read not only the words traced by Agrippa but also a rough inscription scratched above it. ${ }^{41}$

A stereoscope is an instrument which makes surfaces look solid. All pictures in which perspective and light and shade are properly managed, have more or less of the effect of solidity; but by this instrument that effect is so heightened as to produce an appearance of reality which cheats the senses with its seeming truth. ${ }^{42}$

It was Wendell Holmes who would go on to develop the first commercially successful stereoscope.

\section{The Stereoscope and Spatial Vision}

In its first manifestation, the accepted

${ }^{41}$ Holmes "The Stereoscope and the Stereograph" p 745.

${ }^{42}$ Holmes "The Stereoscope and the Stereograph" p 742. 
technical principle of stereoscopic photography advocated a lens separation of two and one-half inches, this being taken as a normative human interocular distance. It was agreed that any more than this would cause the image to to become "distorted," even "monstrous" to our visual sensibility. ${ }^{43}$ The one area of exception to this principle of andromorphic reproduction was landscape photography, where widening the lenticular distance, sometimes to as much as several feet, had the effect of enhancing the depth of field and adding heightened relief - the effect of which, at least in the 1857 view of Hermann von Helmholtz, was "a much clear representation of the form of a landscape than the view of the landscape itself." 44

This fascination with the truthful depiction of reality was one of the defining features of photographic enterprise as it developed during the nineteenth century. Talbot pitched his calotype photographic process as "photogenic drawing," owing nothing to the "skill of the artist and engraver" but instead wholly derived from the "mere action of light

${ }^{43}$ Silverman "The Stereoscope and Photographic Depiction in the late 19th Century" p 748.

${ }^{44}$ von Helmholtz "On the Telestereoscope" p 20. upon sensitive paper." 45 The point to note is that Talbot viewed his process as a method of physical nature recording itself. The photogenic drawing, as the result of physical (optical) and chemical processes, provided ample veracity in "completeness of detail and correctness of perspective."46 Talbot published these thoughts in the instructively titled Pencil of Nature, which, according to the Metropolitan Museum of Art, was "the first commercially published book illustrated with photographs - a milestone in the art of the book greater than any since Gutenberg's invention of moveable type."47

The most extreme example of the ability of stereoscopic photography to produce a hyperspace of nature involved pairing photographs of the moon taken several months apart could produce sufficient parallactic discrepancy to produce a threedimensional visual effect of the moon that is otherwise denied us as the distance involved nullifies our binocular experience.

But if the landscape could be made more landscape-like, and the moon more moon-like,

\footnotetext{
${ }^{45}$ Talbot The Pencil of Nature n.p.

${ }^{46}$ Talbot The Pencil of Nature n.p.

47 "The Pencil of Nature" n.p.
}

for many this simply proved that the stereoscope was an instrument of untruthfulness. Even Brewster would write that only a "special purpose - a colossal statue, for example - could demand a deviation from normal lenticular distance between lens." Otherwise, the artificial relief would be ..." but a trick which may startle the vulgar, but cannot gratify the lover of what is true in nature and art." 48

A median lenticular distance of the human animal sets the defining criteria for a "truthful" visual representational experience, and when the lenticular distance exceeds a normative human quotient, the visual experience of the Stereoscope becomes "untruthful." What we think of as our visual "truth" is already the product of an optical apparatus composed of biomechanical elements. That we can distinguish between a "truthful" and "untruthful" visual truth is defined by generally common agreed experience, as set by a lenticular distance, and not through some absolute of vision or seeing. The significance of this statement is the implication that all seeing is both "truthful" and "untruthful," simultaneously a visual

${ }^{48}$ Brewster The Stereoscope p 147. 
"reality" and a visual "figment."

This should have been an argument for philosophers, but in every other way, the stereographic image was embraced as a visual entertainment specially suited to voyeurism of the exotic, and which we might be described as a class of vicarious "visual tourism." In this model, the "reality" of an image has less importance than the ability of the optical experience to evoke an exotic visual "other."

\section{Table becomes landscape}

If the quintessential focus for a stereographic recording was a cluttered Victoria interior, then "Interior view of a hut ..." is an exceedingly unconventional subject. Instead of the "material plenitude" sought by Crary, here the interior is a largely known state, with our attention being drawn to a spartan dining arrangement for one. Indeed, the emptiness of the hut might be seen to fulfil exactly the kind of domestic void that Crary identifies as central to Victorian bourgeois life. So, do we have here a strangely post-imperial view where the influences of Victorian colonial domesticity have been cast away to reveal a nascent New Zealand interior defined by utilitarian pragmaticism? Maybe, but we have already suggested that, in the small details of the cutlery, we find evidence of the hut as an accessory to normative suburban domesticity. But what we do get in this view is an impulse to participate. With no figures pictured, a setting for one, and our stereoscopic view locating the tableau between our view and the open door, our immersive impulse is to own this setting as our own. At the same time, two alternative visual effects are made present.

The most obvious of these is the place setting itself, which holds the visual foreground of the composition and which, due to this placement, is best able to affect a convincing three-dimensional visual experience of tangibility. But the paradox of this is that the setting appears with very few visual clues to its domestic scale. In a representational transference similar to what Aldo Rossi would play with in the 1980s, the table is transformed into a landscape tableau upon which a bottle, jar, and mug lose their domestic scale and take on the monumentality of "great" buildings.

The other visual effect is, perhaps, even more confronting. Along with the table tableau, the other arresting part of the composition is the framed view of another hut through the open door. However, unlike the table setting, this scene is sufficiently cropped and distant to neutralise lenticular coordination and so render the distant view flat. Indeed, it is so flat that we start to perceive it as a picture within the visual experience. To be clear, we are not suggesting that the exterior view is fake. Yet, it remains a function of stereoscopic involvement that the table setting leaps into binocular view. In contrast, the outside hut remains a flat background with a degree of artificiality - as though a set designer had painted an idealised New Zealand rural setting, providing an exterior appearance in our interior experience.

If we entertain this further, an interesting perceptual paradox occurs. We could wonder that this flat hut in the landscape, seen beyond the spatial reality of our immersive interior, might also be the one we are standing in? It is unlikely that Edgar Richard Williams anticipated such surrealism. But if we allow ourselves to be seduced by this rhetorical imagery, we find a remarkable architectural photograph in which we are shown an interior architecture, a landscape architecture, and nothing in between.

\section{Conclusion}

Following its peak, as a favourite 
entertainment of the late nineteenth-century, interest in the stereoscope declined rapidly between 1910-30. Reasons given for this decline are mixed. It might be that the novelty of the stereoscope had run its course as a popular activity, but there might also be the possibility that the subject of the Great War disadvantaged immersive imagery.

But one undeniable fact is that the decline of the stereoscope occurred in parallel with the rise of cinema. The moving image was a technical advancement in photographic representation, which, like the stereoscope before it, presented an immersive "reality" experience, albeit using a temporal rather than spatial illusion. However, we think there are reasons beyond technological novelty that enabled cinema to so comprehensively replace stereography as a visual entertainment.

Firstly, cinema was defined by a moving image. This meant that the visual experience was longer and, more importantly, with this temporal element, cinema, unlike stereography, lent itself to constructing narrative experience. If the effect of stereoscopic experience was to place a viewer within an image, then this observer suffered for being a passive participant. Cinema, while not challenging its two-dimensional technology until much later, was able to invite active emotional involvement through storytelling.

Secondly, cinema was inherently social. In order to work, the stereoscopic image needed to appeal directly to the binocular experience of an individual. The stereographic experience was not one that wanted to be, or could be, shared. But film, with its collective formality in the cinematic theatre and a narrative involvement that could be lasting, was inherently a shared social activity that reinforced film as an entertainment communion.

In the apparently simple photograph "Interior view of a hut ..." we can find a complex amalgam of these competing values. As an image, its technological processstereography-gave it some additional cultural value for recording the drama of a natural landscape, even as it became a redundant nineteenth-century curiosity for urbanites flocking to the cinema.

And yet, for all its immersive suggestion, the stereograph is a lonely medium devoid of social connection or narrative movement. And so, in this way, "Interior view of a hut ..." ends up an oddly cautionary image in which we are asked to make a choice. Do we stay in the comfort of an interior architecture, with its resonances of bourgeois comfort and stable privilege? Or do we step through into the landscape architecture, whose visual qualities are soon to become trampled under egalitarian entitlement and picturesque nationalism? 


\section{REFERENCES}

Belich, James Paradise Reforged: A History of the New Zealanders from the 1880s to the Year 2000. Auckland: Penguin, 2001.

Benjamin, Walter "A Short History of Photography" Screen (Spring 1972) 13(1):5-26.

Brewster, David The Stereoscope: Its History, Theory, and Construction with Its Application to the Fine and Useful Arts and to Education London: J. Murray, 1856.

Colligan, Colette "Stereograph" Victorian Review (Spring 2008) 34(1):75-82

Crary, Jonathan Techniques of the Observer: On Vision and Modernity in the Nineteenth Century Cambridge, Mass.: MIT Press, 1990.

Donnelly, Peter "Social Climbing: A Case Study of the Changing Class Structure of Rock Climbing and Mountaineering in Britain" Studies in the Sociology of Sport: Refereed Proceedings of the 2nd Annual Conference of the North American Society for the Sociology of Sport, Fort Worth, Texas, November 1981 ed. Aidan O. Dunleavy, Andrew W. Miracle \& C. Roger Rees Fort Worth: Texas Christian University Press, 1982.

"Dunedin Photographic Society" Evening Star (17 November 1898):2.

"English Extracts" New Zealand Spectator and Cook's Strait Guardian (29 May 1852) 8(712):3.

"Friday, June 23, 1899" The Otago Daily Times (23 June 1899):4.

"Gawne's Worcester Sauce [advertisement]" Southland Times (4 May 1889):3.

Gilchrist, Paul "The politics of totemic sporting heroes and the conquest of Everest" Anthropological Notebooks (2006) 12(2):35-52.

Giorgio B "Walker and Hall" A Small Collection of Antique Silver and Objects of Vertu: The What is? Silver Dictionary (accessed 8 July 2021): silvercollection.it/ENGLAWALKER\&HALL.html

Hansen, P.H. "Albert Smith, the Alpine Club, and the Invention of Mountaineering in Mid-Victorian Britain" Journal of British Studies
(July 1995) 34(3):300-324.

"Hartley's" Wikipedia: The Free Encyclopedia (updated 3 February 2021): en.wikipedia.org/wiki/Hartley\%27s

Holmes, Oliver Wendell "The Stereoscope and the Stereograph" The Atlantic (June 1859) 3(20):738-748.

Hunt, Robert "The Stereoscope" The Art Journal (March 1856) 18:118-120.

Johnston, Margaret \& Eric Pawson "Challenge and Danger in the Development of Mountain Recreation in New Zealand, 1890-1940" Journal of Historical Geography (April 1994) 20(2):175-186.

Kearns, Robin \& Joe Fagan "Sleeping with the past? Heritage, Recreation and Transition in New Zealand Tramping Huts" New Zealand Geographer (August 2014) 70(2):116-130.

"The New Stainless Rustless Cultery [advertisement]" Tuapeka Times (24 November 1920):4.

Norrie, J.S. "Photography [advertisement]" New Zealander (14 March 1860):2.

"Notes and Queries" Otago Witness (20 February 1907):47.

O'Toole, Laurence Pornocopia: Porn, Sex, Technology and Desire London: Serpent's Tail, 1998.

"The Pencil of Nature: 1844-1846" The Met The Metropolitan Museum of Art (accessed 6 July 2021): metmuseum.org/art/collection/search/267022.

Shurtleff, William and Akiko Aoyagi History of Worcestershire Sauce (18372012): Extensively Annotated Bibliography and Sourcebook Lafayette, CA: Soyinfo Center, 2012.

Silverman, Robert J. "The Stereoscope and Photographic Depiction in the late 19th Century" Technology and Culture (October 1993) 34(4):729-756

Spiro, Lisa History through the Stereoscope: Stereoscopy and Virtual Travel Houston, TX: Connexions, 2012: hdl.handle.net/1911/109667 
"Sydney Photographic Exhibition" Evening Star (14 November 1899):3.

Talbot, William Henry Fox The Pencil of Nature London: Longman,

Brown, Green and Longmans, 1844.

"Town and Country" Lyttelton Times (29 November 1909):6.

Trotter, David "Stereoscopy: Modernism and the Haptic" Critical

Quarterly '(December 2004) 46(4):38-58.

"Valuable Photographic Camera for Sale [Advertisements]" Lyttelton

Times (26 May 1860): 5.

von Helmholtz, Hermann "On the Telestereoscope" Philosophical

Magazine (1858) 15(97):19-24.

von Helmholtz, Hermann Treatise on Physiological Optics Vol. 3 Menasha,

WI: The Optical Society of America, 1924.

Wendling, Ame E. "Sovereign Consumption as a Species of Communist Theory: Reconceptualising Energy" Reading Bataille Now ed. Shannon

Winnubst Indianapolis, Indiana University Press, 2007: 35-53.

"Wharf Stores, Shortland Street [advertisement]" New Zealander (5 August 1857):1.

Wheatstone, Charles "Contributions to the Physiology of Vision:-Part the First. On some remarkable, and hitherto unobserved, Phenomena of Binocular Vision" Philosophical Transactions (1838) 128:371-394.

Wilkniss, Kelly "Enamelware - a collector's guide" My Soulful Home (c2014): mysoulfulhome.com/my-soulful-home/enamelwarecollectors-guide

Zimmerman, Claire. Photographic Architecture in the Twentieth Century. Minneapolis: University of Minnesota Press, 2014. 